\title{
Probiotics in Critically Ill Patients: An Umbrella Review
}

\author{
Amirreza Naseri ${ }^{1} \odot$, Sepideh Seyedi-Sahebari ${ }^{2} \odot$, Ata Mahmoodpoor ${ }^{3}$, Sarvin Sanaie ${ }^{4} \odot$
}

\begin{abstract}
Objectives: Probiotics are live microorganisms which when administered in adequate amounts confer a health benefit on the host. Because of the wide usage of antibiotics, acute changes in diet, and the stress of illness, critically ill patients' homeostasis of the gut microbiome can be disrupted during intensive care unit (ICU) confinement; probiotics are suggested as a beneficial intervention in critically ill patients. We tried to give an overview of the effects of probiotic supplements in critically ill patients based on published systematic reviews (SRs) and meta-analyses (MAs). Data sources: A systematic search was performed in four databases as well as hand searching.

Study selection: The results were independently screened in two title/abstracts and full-text stages.

Data extraction: Any reported outcomes in each study were extracted, using a data extraction table.

Data synthesis: A wide range of outcomes of using probiotic supplements in critically ill patients have been reported in 20 included studies. Based on the current knowledge, we can say that probiotics may reduce the rate of ventilator-associated pneumonia, nosocomial pneumonia, the overall infection rate, duration of mechanical ventilation, and antibiotic use in critically ill patients, but there is not a significant association between using the probiotics and mortality, length of hospitalization, and incidence of diarrhea.

Conclusion: Despite the various beneficial effects of probiotics in critically ill patients, there is not yet much evidence supporting the routine use of these supplements and further well-designed multicenter trials are needed to provide "evidence-based" recommendations.

Keywords: Critical illness, Intensive care units, Probiotics, Systematic review, Umbrella review.

Indian Journal of Critical Care Medicine (2022): 10.5005/jp-journals-10071-24129
\end{abstract}

\section{Study Highlights}

- In this umbrella review, we investigated the effects of probiotic supplements in critically ill patients to give an overview of any reported outcome in systematic reviews and meta-analyses.

- Probiotics have been reported to reduce the rate of ventilatorassociated pneumonia (VAP), nosocomial pneumonia, the overall infection rate, duration of mechanical ventilation, and antibiotic use in critically ill patients, but they have shown no or a little efficacy in reducing the rate of mortality and length of stay in hospital.

- The low quality of included studies is one of the most common limitations in the included systematic reviews. Our risk of bias assessment results indicated a high level of concerns about methodological misconduct in our included systematic reviews, too.

\section{INTRODUCTION}

Probiotics are nonpathogenic live microorganisms mainly bacteria, yeasts, or fungi, which are effective for the human body's health especially for the digestive system. ${ }^{1}$ They can be found in yogurt or other fermented food or supplements. According to the World Health Organization (WHO) and Food and Agriculture Organization of the United Nations (FAO) definition, probiotics are "Live microorganisms which when administered in adequate amounts confer a health benefiton the host". ${ }^{2}$ In recent years, the use of these supplements has become popular because of their benefits on human health, especially in infectious diseases, approved in numerous studies. ${ }^{3-5}$ Probiotics contain a variety of microorganisms, but mostly they belong to two groups of bacteria called Lactobacillus and Bifidobacterium. These supplements help the body maintain its health by replacing "good" bacteria in case of elimination by antibiotics with balancing the number of "good" and "bad" bacteria and also influencing our body's immune response. ${ }^{6}$ Although probiotics mostly affect the digestive
1,2Student Research Committee, Tabriz University of Medical Sciences, Tabriz, Iran; Research Center for Evidence-based-Medicine, Iranian EBM Center: A Joanna Briggs Institute (JBI) Center of Excellence, Tabriz University of Medical Sciences, Tabriz, Iran

${ }^{3}$ Department of Anesthesiology and Critical Care, Faculty of Medicine, Tabriz University of Medical Sciences, Tabriz, Iran

${ }^{4}$ Research Center for Integrative Medicine in Aging, Aging Research Institute, Tabriz University of Medical Sciences, Tabriz, Iran

Corresponding Author: Sarvin Sanaie, Research Center for Integrative Medicine in Aging, Aging Research Institute, Tabriz University of Medical Sciences, Tabriz, Iran, Phone: +98 9143116744, e-mail: sarvin so2000@yahoo.com

How to cite this article: Naseri A, Seyedi-Sahebari S, Mahmoodpoor A, Sanaie S. Probiotics in Critically III Patients: An Umbrella Review. Indian J Crit Care Med 2022;26(3):339-360.

Source of support: This work was supported by Deputy for Research of Tabriz University of Medical Sciences.

Conflict of interest: None

system, they have a broad range of activities affecting other parts of the body, such as skin and urinary tract, too.,

Previously, clinicians' interest in the microbiome was only limited to the time of occurrence of an infection in the body, but it seems that it is time for a change in this insight. A systematic review (SR) of existing meta-analyses (MAs) performed in 2017 provided a critical overview of the use of probiotic supplements in physiologic and pathological conditions and stated that the evidence-based effects of probiotics were only for antibiotic-associated and Clostridium difficile-associated diarrhea and respiratory tract infections, but it also stated a need for further well-conducted studies for ventilator-associated pneumonia (VAP) patients in 
intensive care unit (ICU). ${ }^{9}$ In 2017, a Cochrane Overviews of Reviews about preventive interventions of probiotics in clinical practice found that whether none of 16 included Cochrane SRs provided high-quality evidence for any outcome, but probiotics decreased the incidence of diarrhea and upper respiratory tract infections, need for antibiotics, and absences from school due to colds and also VAP. ${ }^{10}$ Probiotics, with or without a combination of prebiotics, are suggested as a beneficial intervention in critically ill patients. Because of the wide usage of antibiotics, acute changes in diet, and the stress of illness, patients' homeostasis of the gut microbiome can be disrupted..$^{11}$ In this condition, probiotics can sustain the gut microbiota in the patients ${ }^{12}$ and prevent opportunistic infections that can live in the absence of protective gut microorganisms. ${ }^{13}$ Prevention and treatment of various infections, diarrhea, and perioperative complications in transplant patients ${ }^{14}$ are some of the reported benefits of probiotic supplements.

The high level of risk of bias (RoB) in trials makes the existing data inconclusive regarding the routine usage of probiotics in critically ill patients. ${ }^{15,16}$ According to Canadian Critical Care Nutrition Guidelines, the use of probiotics should be considered in critically ill patients, except for an unsafe one, Saccharomyces boulardii. This update was after adding 12 randomized controlled trials (RCTs) conducted from 2009 until 2013. Aggregation of the results of these studies with earlier trials suggested a reduction in VAP with the use of these supplements in critically ill patients. ${ }^{17}$ Society of Critical Care Medicine (SCCM) and American Society for Parenteral and Enteral Nutrition (ASPEN) do not recommend the routine use of these supplements in ICU, ${ }^{18}$ and the German Society for Nutritional Medicine (DGEM) considers "may" recommendation to be justified. ${ }^{19}$ When looking for the best evidence, SRs and MAs are at the top of the pyramid; so, we are taking to the next level and design this SR of SRs, also called umbrella review, to investigate the effects of probiotic supplements in critically ill patients to give an overview of any reported outcome in SRs and MAs to reach the most reliable results.

\section{Methods}

A systematic search was performed until September 2020 in PubMed, ScienceDirect, EMBASE, and Cochrane database for SRs with (Probiotic OR synbiotic) AND (Critical Care OR Intensive Care Unit OR Critical III OR ICU) AND (systematic review OR meta-analysis) keywords and without any filters. Results were imported to EndNote software, and after adding results of hand searching to these records, two authors independently reviewed the identified title/ abstracts and full texts in two stages and selected articles which met our eligibility criteria.

The inclusion criteria were as follows: (1) SR journal articles; (2) the population of the study being adult critically ill patients; and (3) the intervention of using probiotics with or without combination with prebiotics. The exclusion criteria were as follows: (1) other types of studies; (2) studies in languages other than English; (3) animal studies; (4) studies of neonates or children; and (5) conference abstracts because of a lack of enough information.

The RoB assessment of studies included in this umbrella review was done by two authors using risk of bias in systematic reviews (ROBIS) tool, which is designed specifically to assess the RoB in SRs. Any disagreement between the researchers is resolved by referring to the corresponding author. ROBIS tool is completed in three phases, and the first phase assesses the relevance of the study which is optional. The second phase of the tool identifies any concerns with the process, including the appreciate eligibility criteria, selection of the studies, data collection and study appraisal, and data synthesis, and finally, the third phase is the judgment of overall RoB in the $S R$, so this tool assesses the RoB in reviewing process, results, and even conclusion. ${ }^{20}$

The data extraction was done independently by two authors with a data extraction table, including studies name, the number of included articles, search databases, interventions and comparisons, quality assessment methods, study population, and outcomes. Flowchart 1 is preferred reporting items for systematic reviews and meta-analyses (PRISMA) 2009 flow diagram, ${ }^{21}$ and detailed information about searching, selecting, and reasons for excluded studies are presented in this flowchart.

\section{Results}

The database search resulted in 559 records, and finally, 20 studies were included in umbrella review. A wide range of outcomes of

Flowchart 1: PRISMA flow diagram

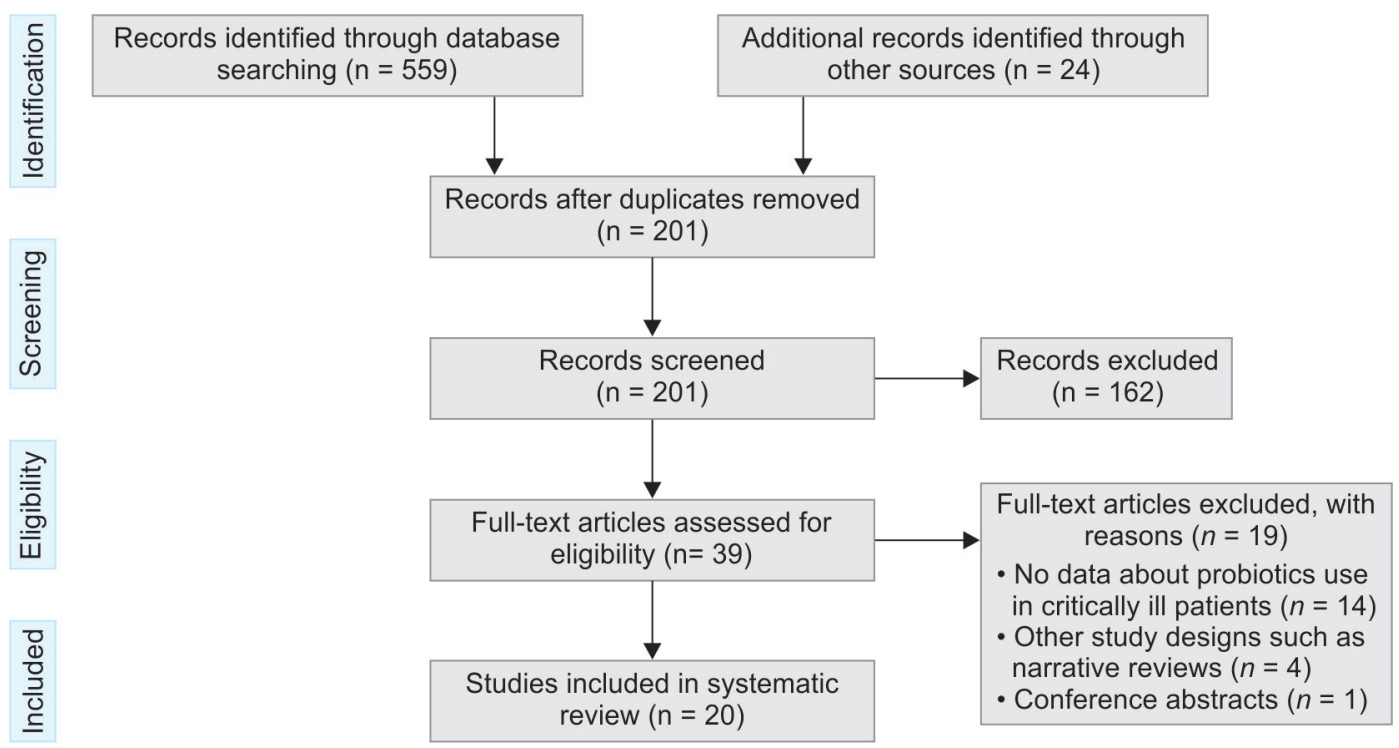


using probiotic supplements in critically ill patients has been reported in the studies. All the related data about using probiotic supplements in critically ill patients are summarized in Table 1.

\section{Ventilator-associated Pneumonia}

Eleven studies have investigated the relationship between using probiotic supplements and the incidence of VAP. Eight of these studies, including the study with the largest sample size ${ }^{22}$ and the latest one ${ }^{23}$ found probiotic supplementation as an effective intervention. Three studies ${ }^{24-26}$ reported the results of the subgroup analysis by the route of administration, and except for one study, the results were still significant when the oral form was excluded. The subgroup of different probiotic regimens in two studies ${ }^{22,26}$ showed a better efficacy for Lactobacillus rhamnosus compared to others.

\section{Incidence of Nosocomial Pneumonia}

Four studies assessed the efficacy of probiotic supplements in reducing the incidence of nosocomial pneumonia, and a statistically significant difference was seen in the largest scale study. ${ }^{27}$

\section{Duration of Mechanical Ventilation}

Seven studies reported the results regarding the duration of MV. Until the latest published $\mathrm{SR}^{23}$ none of the studies found a significant change with the use of probiotics; but the latest SR, with the largest sample size, found it effective.

\section{All Infections}

There are four SRs giving information in this regard. The last and largest-scale study ${ }^{28}$ found that probiotics were effective in reducing the rate of infections.

\section{Urinary Tract Infection (UTI)}

Only one study gave information in this regard. In 2012, a SR ${ }^{25}$ with pooling data from two trials found that probiotics were not associated with a decrease in the incidence of UTI as one of their secondary goals.

\section{Catheter-related Bloodstream Infection (CR-BSI)}

Catheter-related bloodstream infection (CR-BSI) was the other outcome reported in two of our included SRs, and none of them found a significant relation.

\section{Antibiotic Use}

Probiotic efficacy in reducing antibiotic use was investigated in two SRs, and the latest one with a larger scale ${ }^{28}$ found it good complementation for antibiotic therapy of critically ill patients.

\section{Antibiotic Use for VAP}

Antibiotic use for VAP has been reported in three SRs, with totally different results. Three studies investigated this outcome, and the antibiotic use was not different between placebo and probiotic group in one study, while in the other two ones, antibiotic usage was higher in probiotic and placebo group.

\section{Septic Complication}

None of the three included trials that reported the rate of bacteremia in the MA of Siempos et al. ${ }^{24}$ showed any case of bacteremia in the probiotic group. Also, there was no infection or bacteremia due to a probiotic strain used in Barraud et al. ${ }^{27}$ SR, based on the results of nine studies.

\section{Overall Mortality}

In 2017 , a study of probiotics efficacy in preventing VAP ${ }^{29}$ pooled 90-day mortality data of the studies as one of their secondary outcomes. In two studies, supplementation was not associated with a reduction in 90-day mortality. In addition, a 28-day mortality rate was also reported and the difference was not significant. Moreover, there was no significant difference in the overall mortality rate, too.

\section{Hospital and Intensive Care Unit Mortality}

Twelve studies compared the rate of hospital mortality between intervention and control groups but none of them could detect a significant efficacy in this regard. Similar to hospital mortality, 12 studies gave information on ICU mortality. Except for one SR, ${ }^{13}$ efficacy was not significant in this regard, too.

\section{Length of Hospital and Intensive Care Unit Stay}

Six different SRs found no changes in the hospital length of stay (LOS) with using probiotics in ICU patients. Thirteen studies investigated ICU LoS as one of their outcomes, and except for two of them, ${ }^{24,27}$ they could not show an effect of probiotics in reducing the length of stay in ICU.

\section{Diarrhea}

Diarrhea was the most common reported adverse event in all studies. Eleven studies compared the rate of diarrhea between probiotic supplement users and the control group but using probiotics was not associated with changes in the rate of diarrhea in any of these studies.

\section{Safety Issues}

In 2010, Whelan et al. ${ }^{30}$ investigated 72 different-type studies for assessing the safety of probiotics. Twenty-one studies included in this SR were performed in critically ill patients. Probiotics were tolerated well in most of these studies, and no serious side effects were reported. Also, another SR of the safety of probiotics in $2014^{31}$ evaluated the safety of probiotics in humans and animal models. They found that critically ill patients besides the immunecompromised and postoperative patients are the most at-risk populations to develop adverse effects.

\section{Others}

In 2020, a SR of complementary and alternative medicines' effect on sleep quality and quantity in adult intensive care patients found no relevant data meeting their inclusion criteria about probiotics; so, to the best of our knowledge, no studies have investigated this outcome. $^{32}$

Probiotics' potential to modulate the inflammatory process was investigated in a SR in 2019. ${ }^{33}$ This study includes only one RCT with a population of critically ill patients ${ }^{34}$ showing that probiotics reduce the level of serum interleukin 6 (IL-6) and prolactin (PCT), but also a significant increase in serum protein $C$ levels is observed.

\section{Risk of Bias Assessment}

Results of the RoB assessments are summarized in Table 2 and Figure 1. In terms of eligibility criteria, there was not much concern and most of the studies had low RoB based on our assessment. In the second domain of ROBIS tool, which assesses the RoB in the selection of the studies, the most common concern was about efforts to minimize errors in the selection of the studies. In the data collection and study appraisal domain, most of the studies did not report any try to reduce error in data collection and RoB 


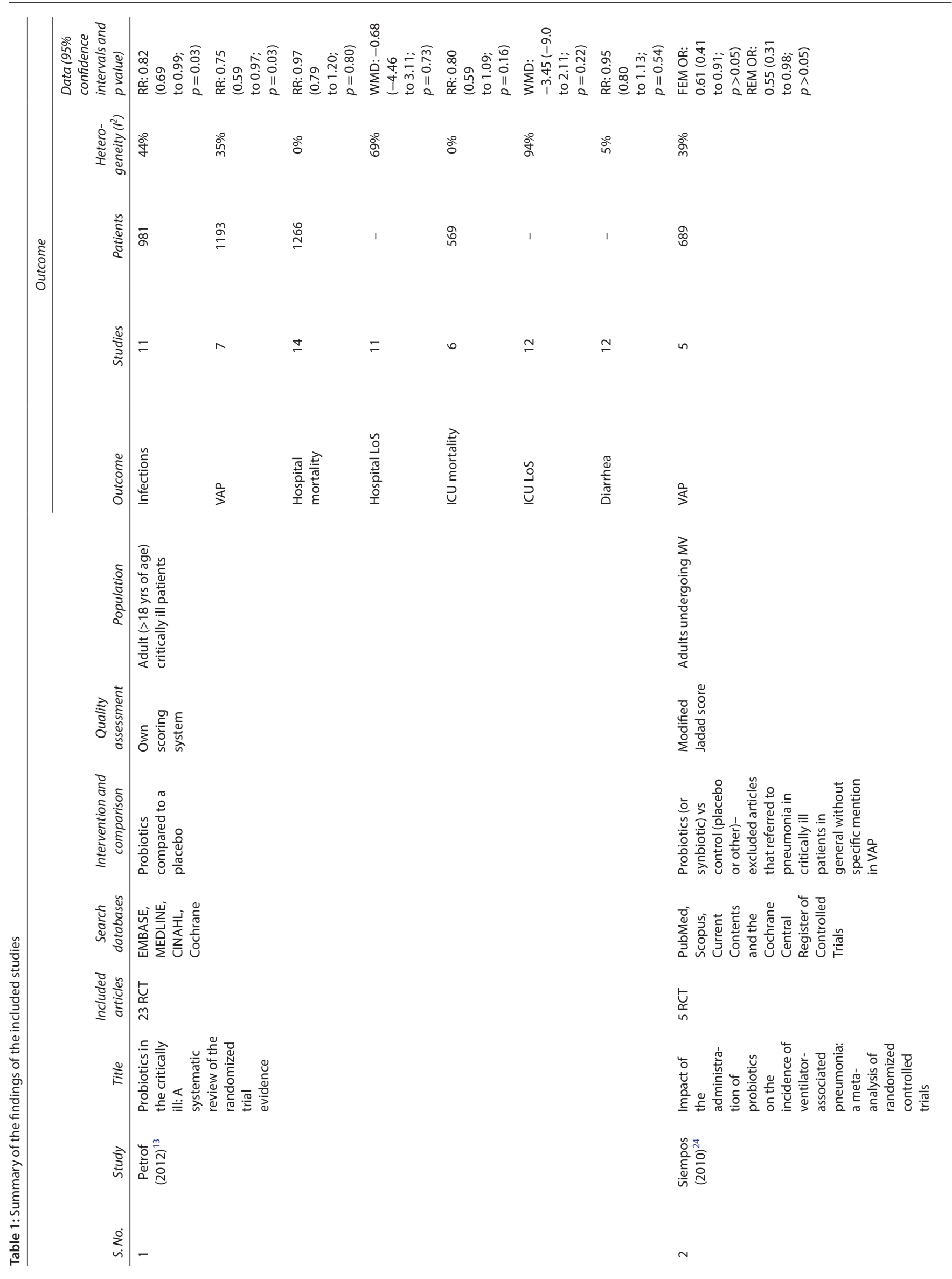




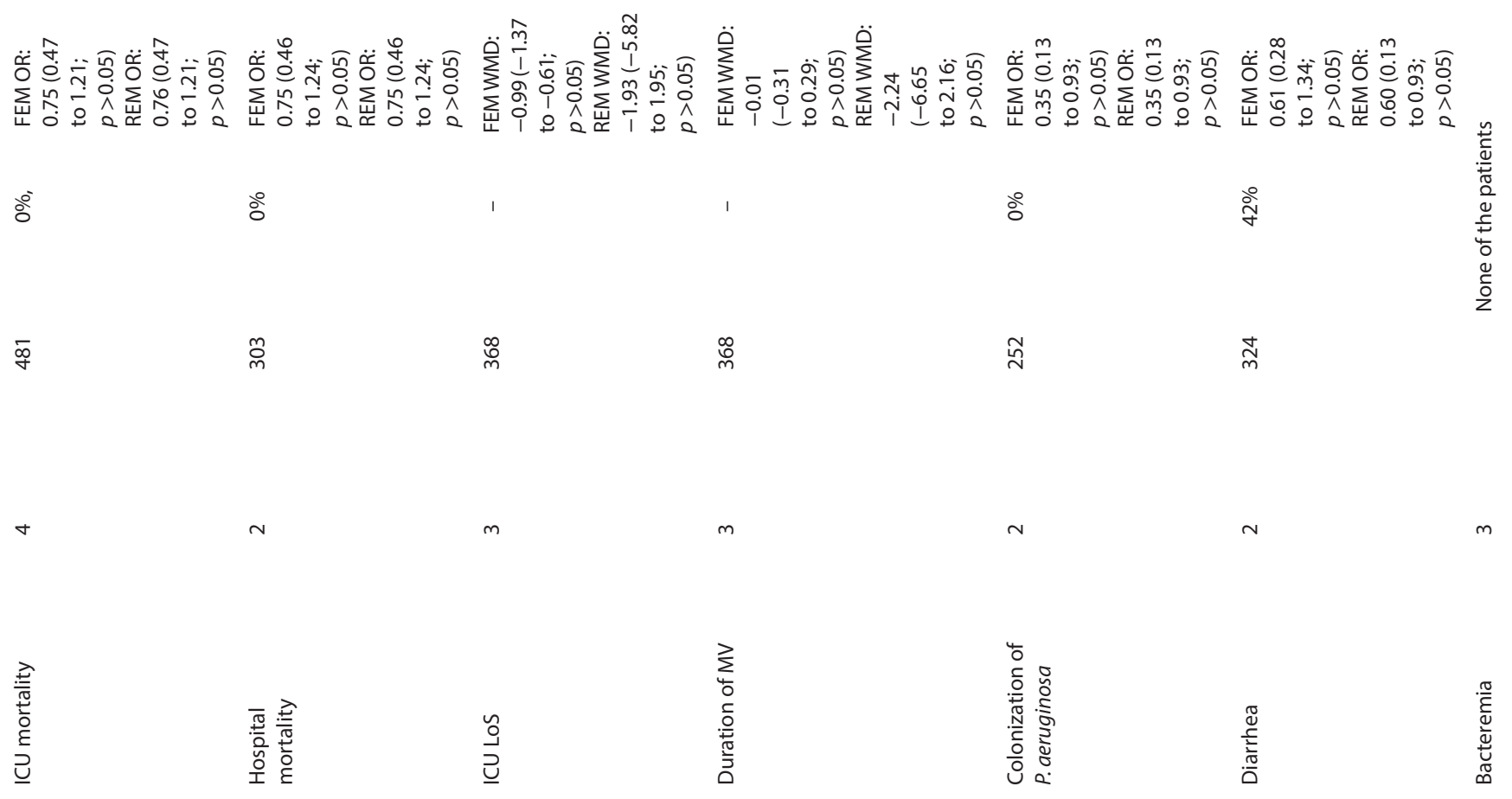




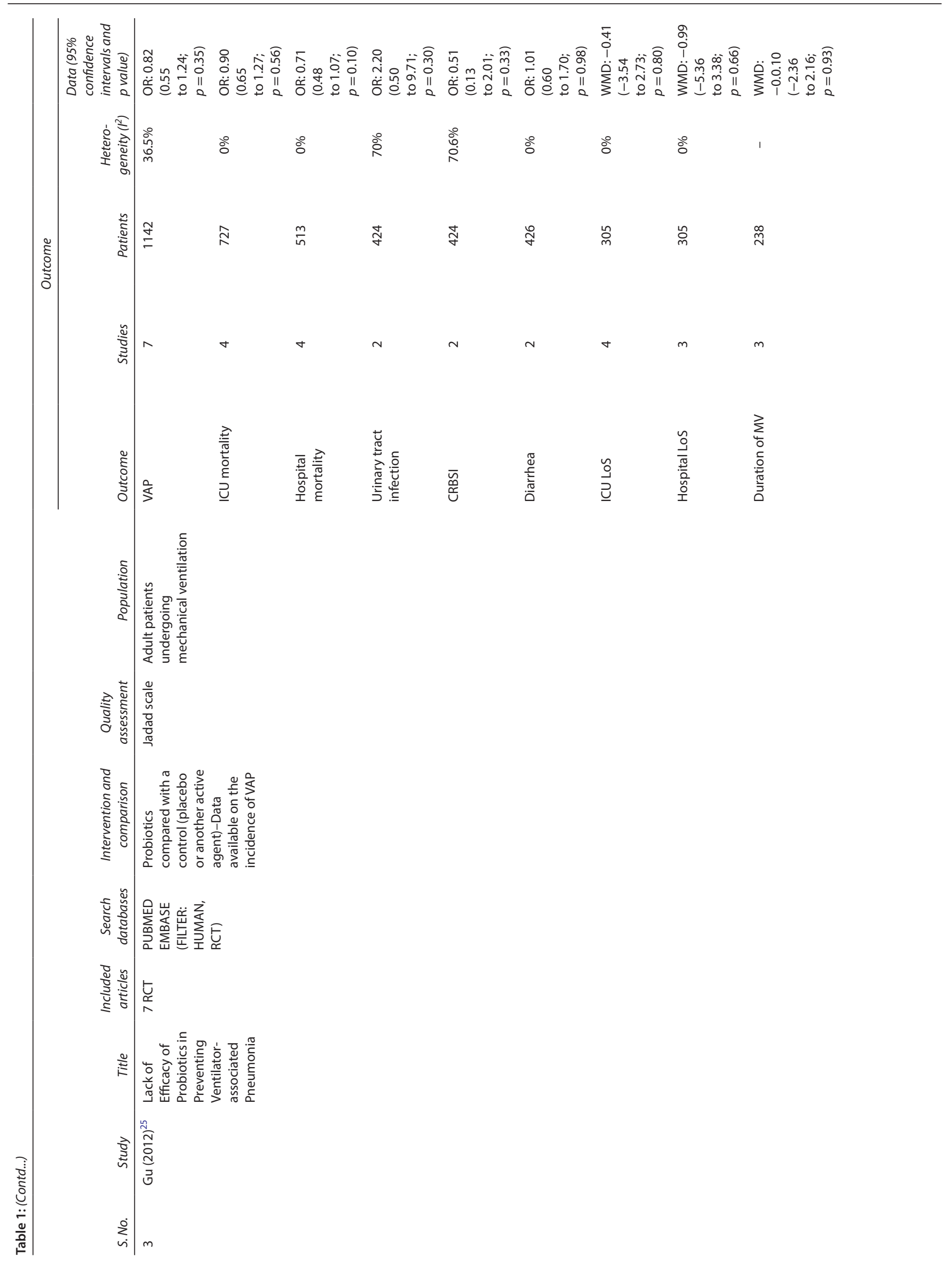




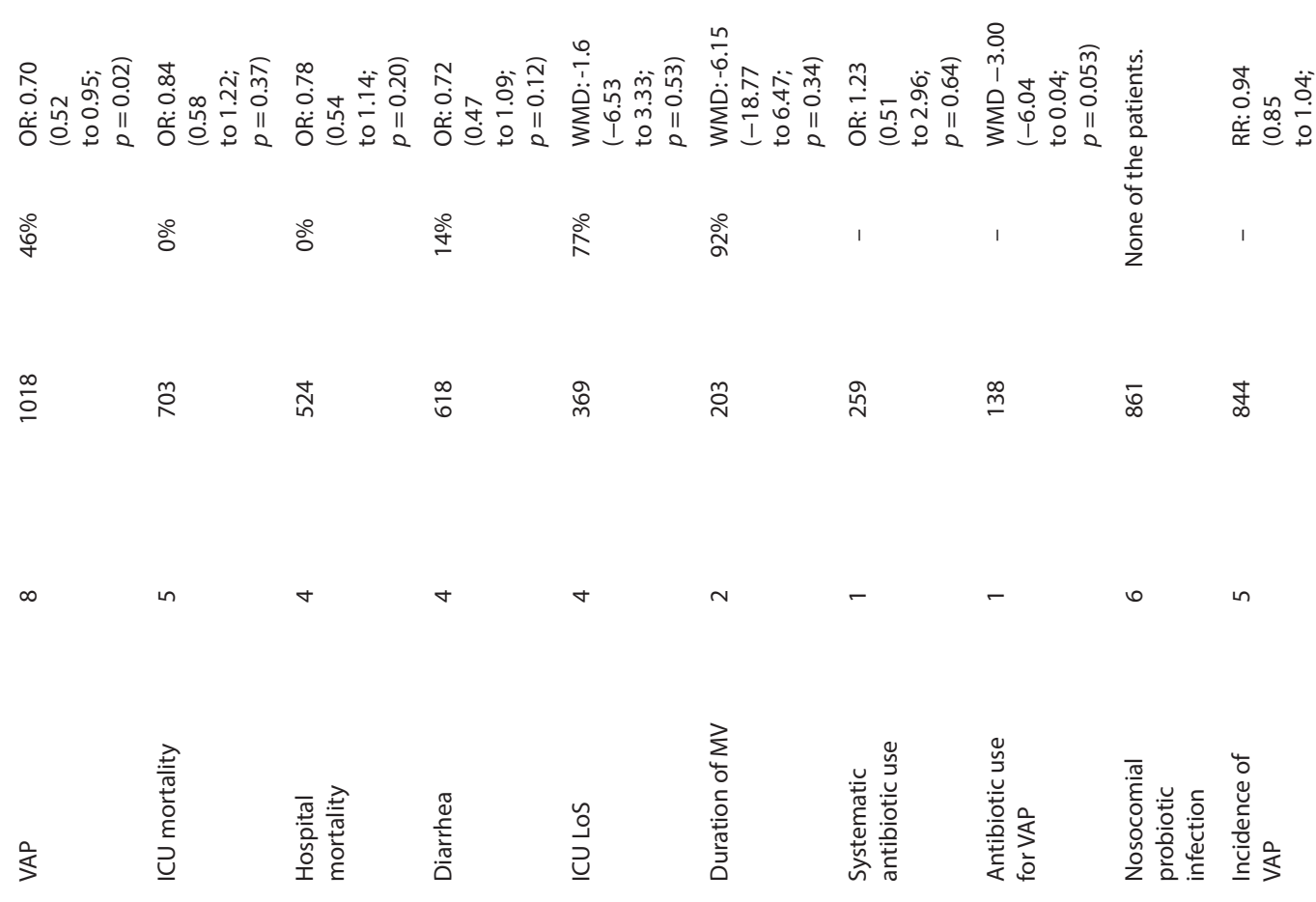

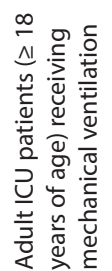

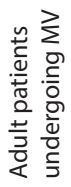

总

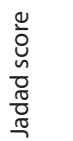

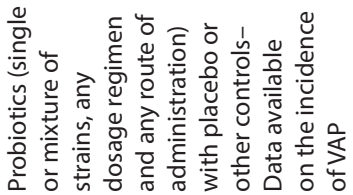

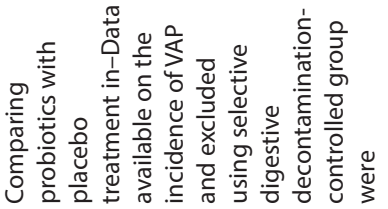

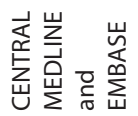

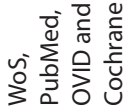

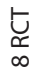

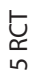

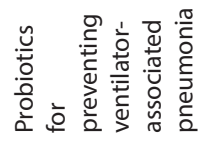

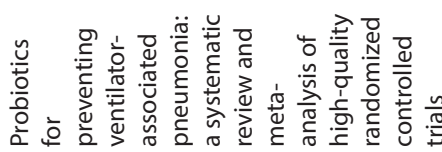

竞

ริำ 


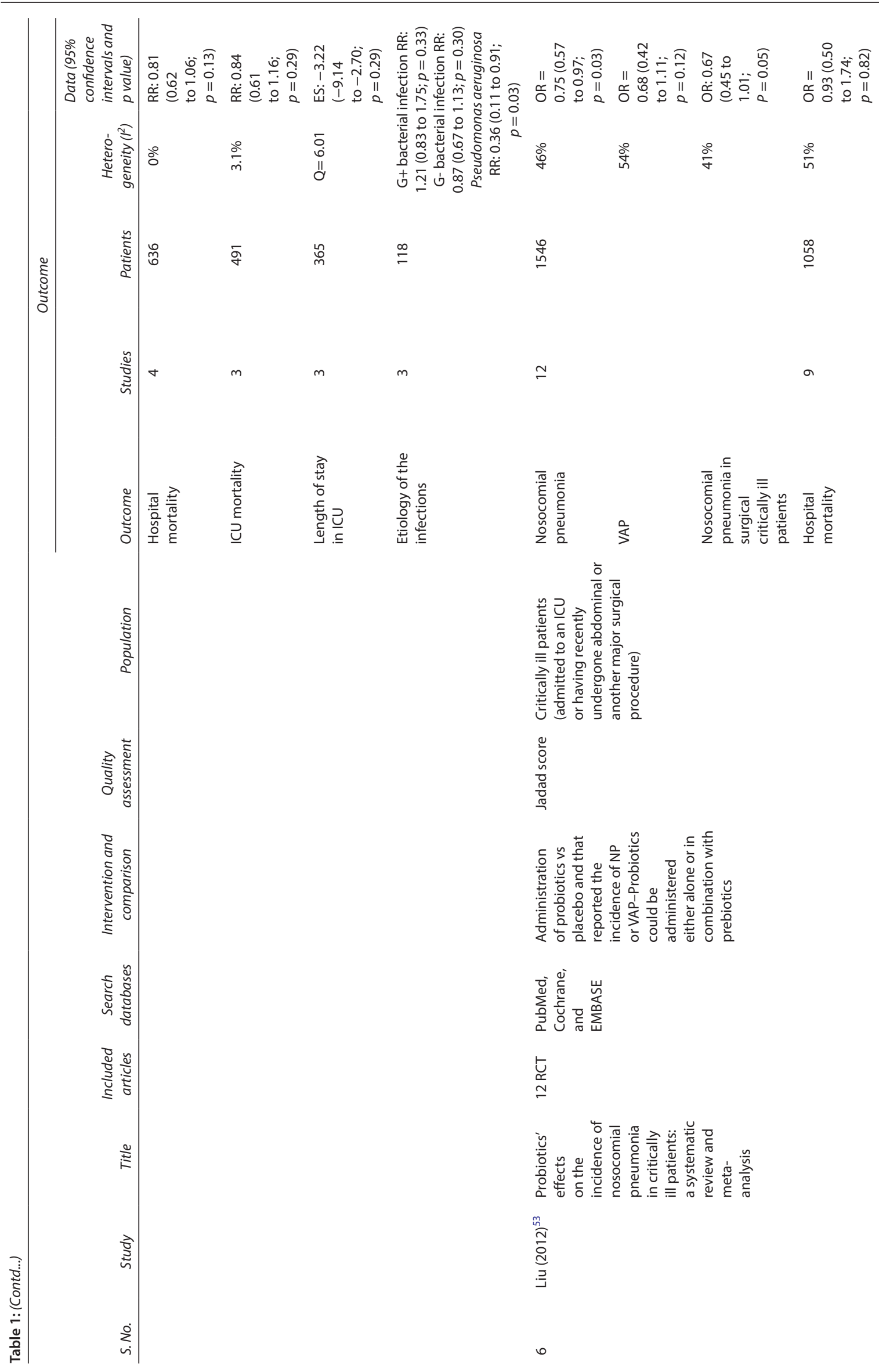




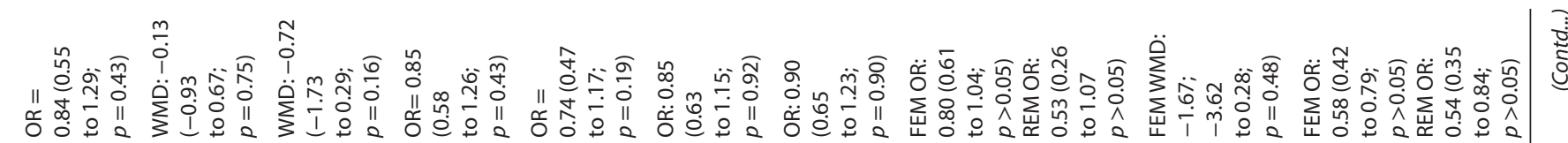

\&े

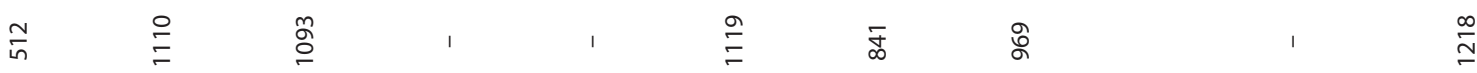

$\infty$

6

m

a

$\infty$

$a$

우

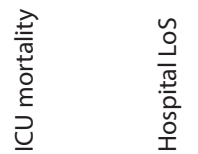

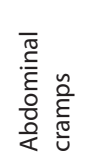

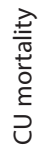

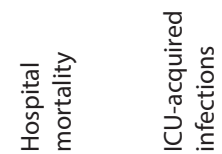

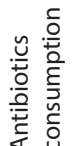

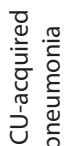

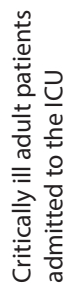

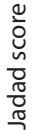

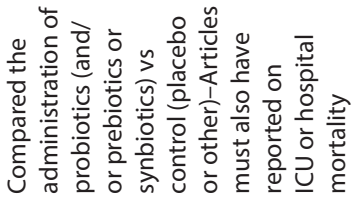

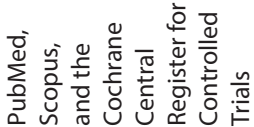

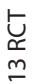

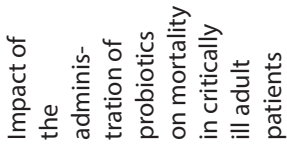

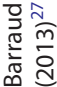




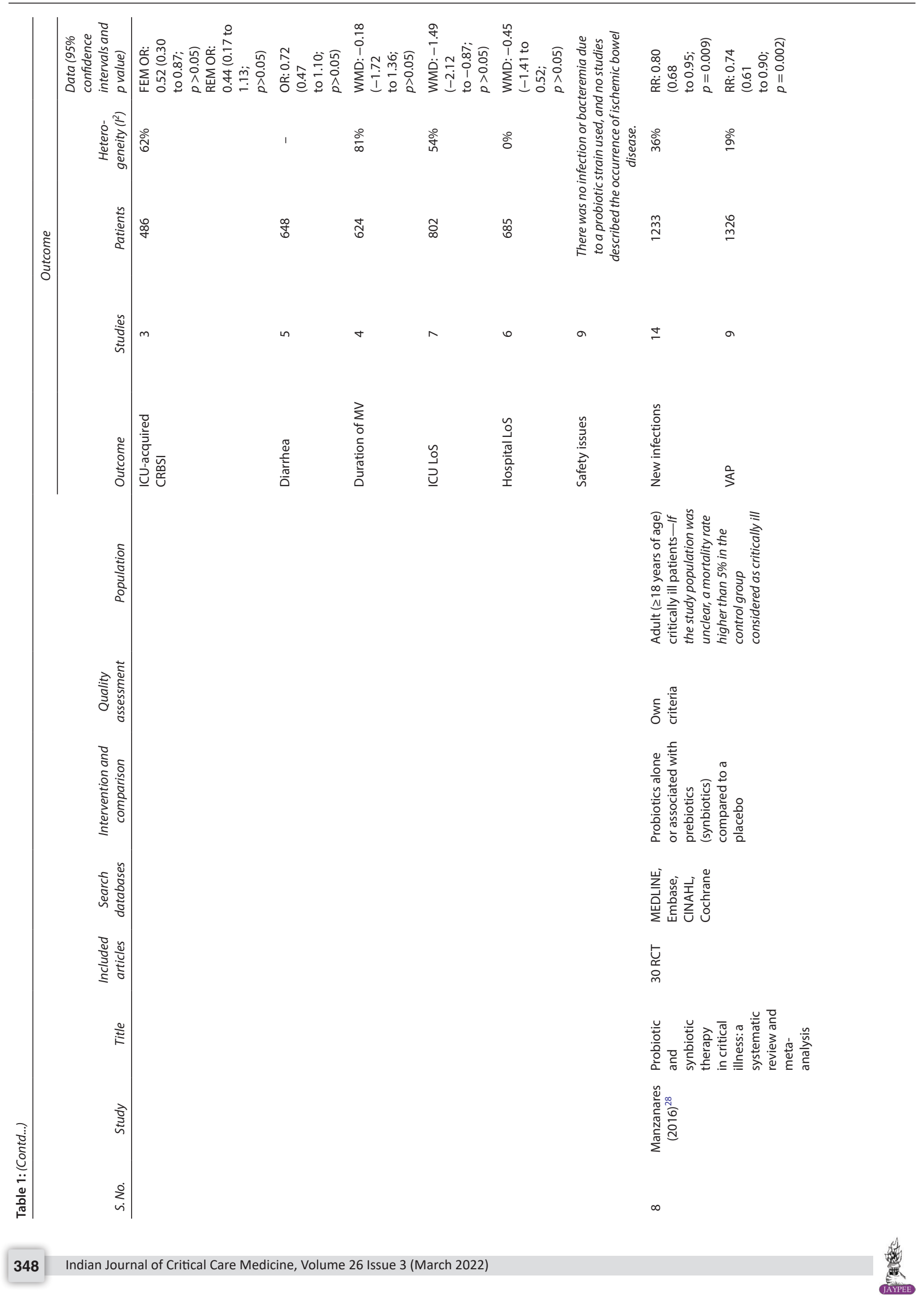




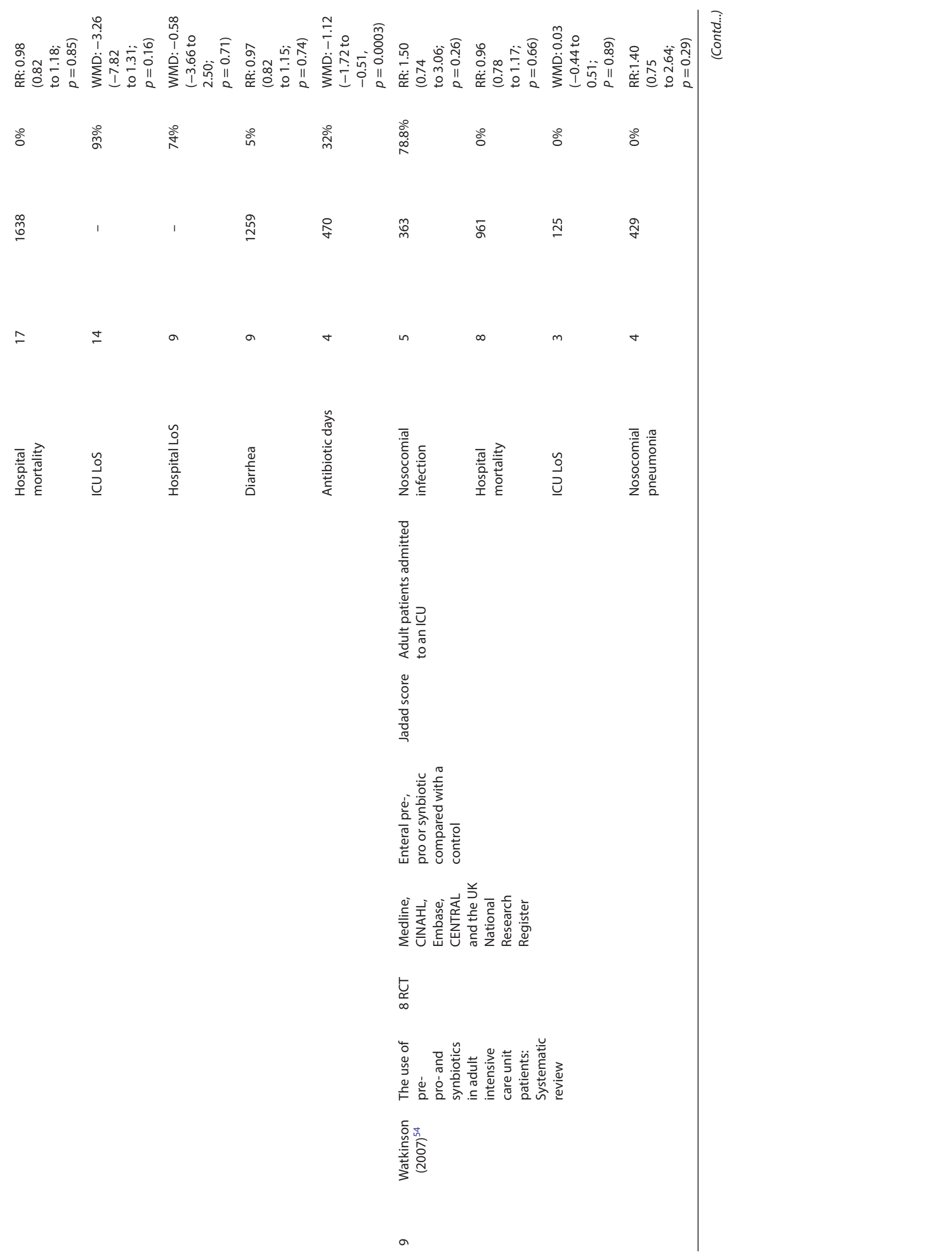

$a$ 


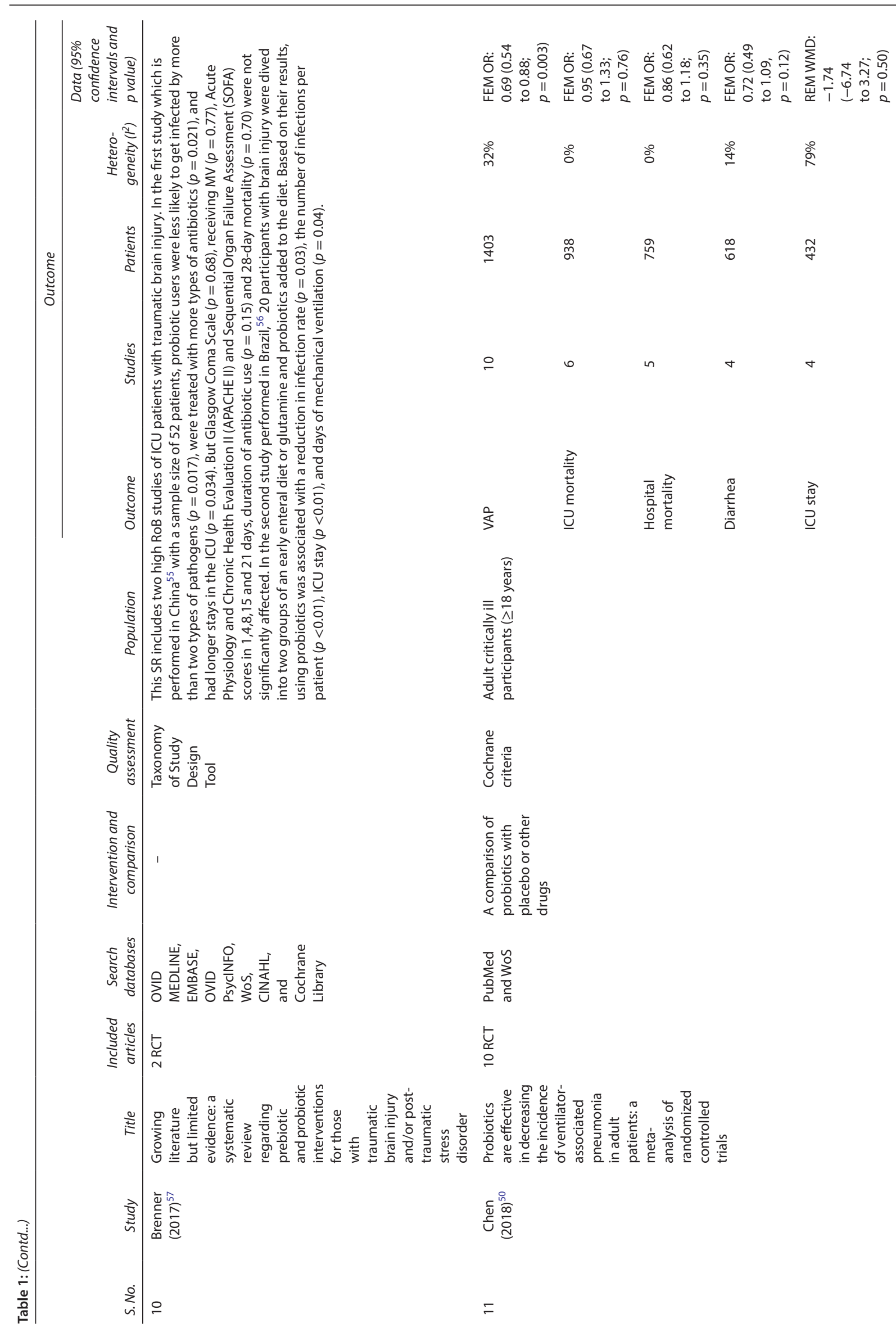




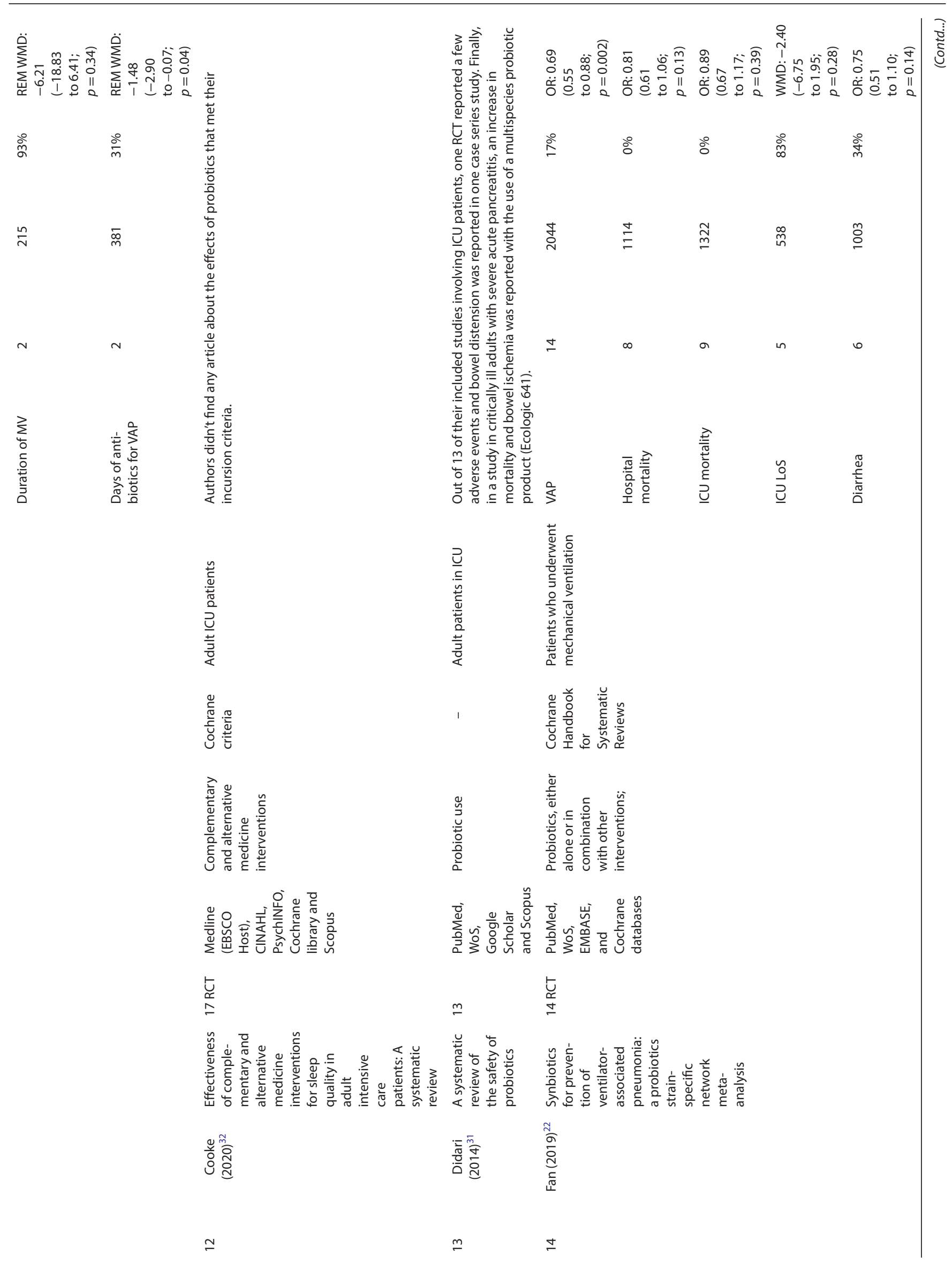




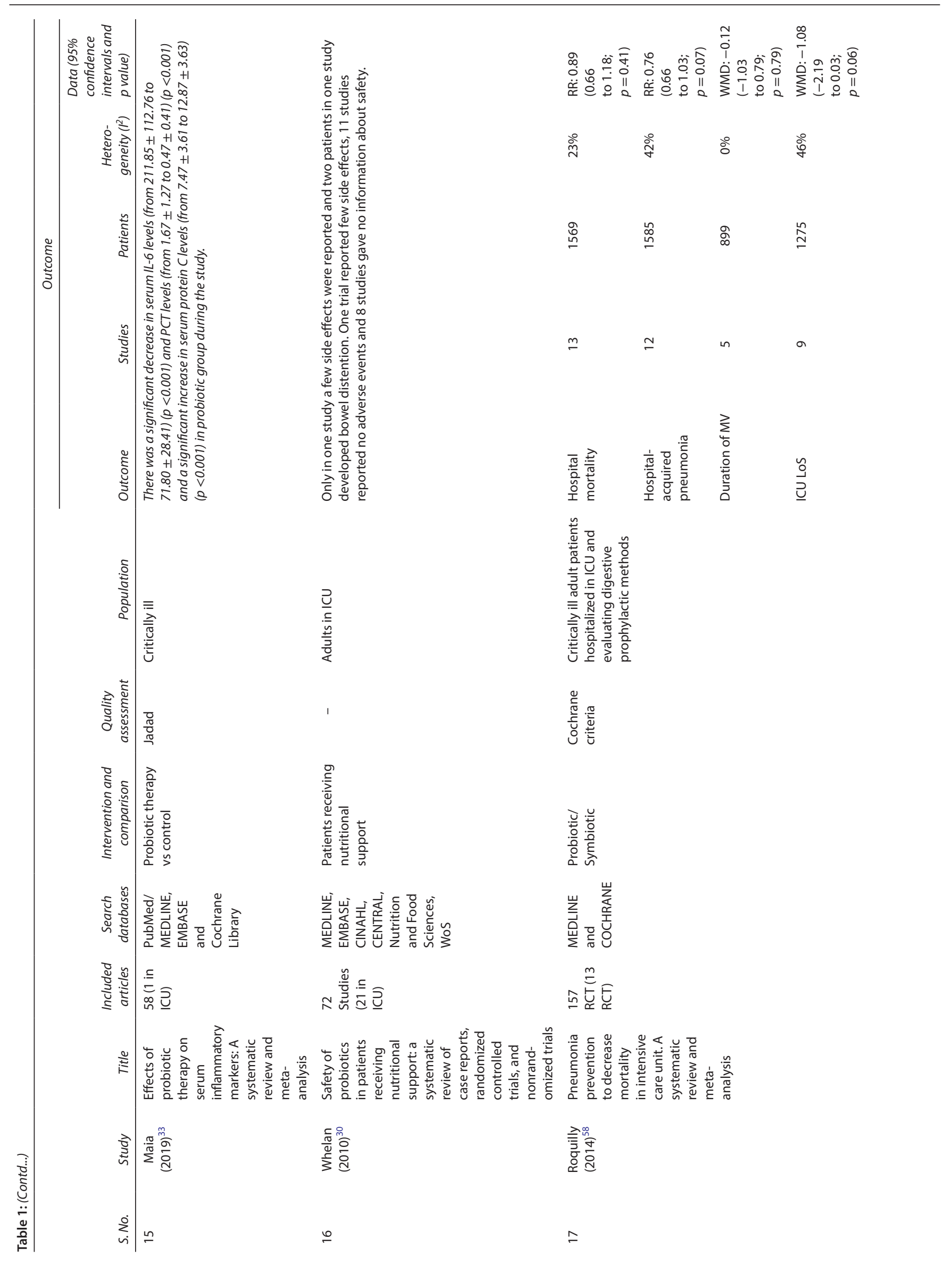




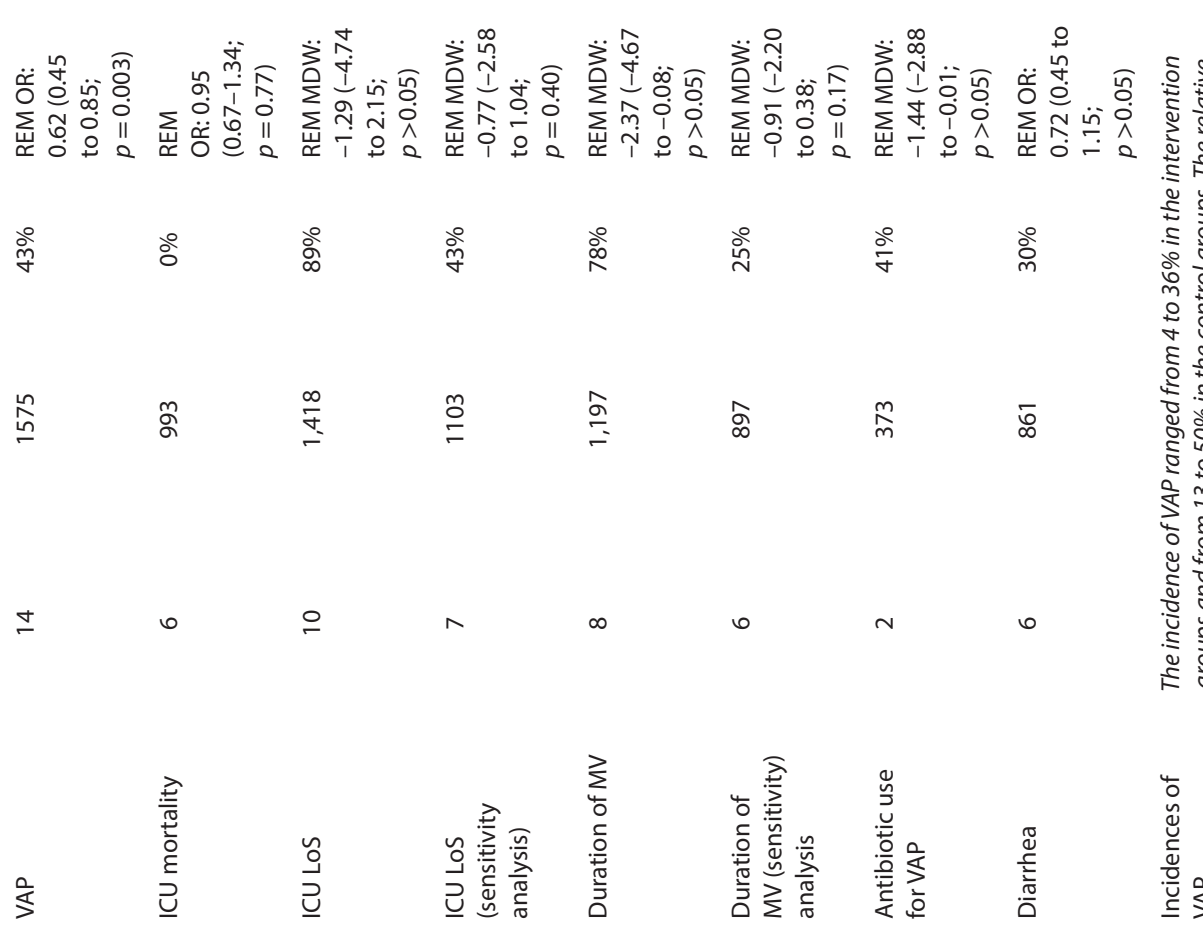

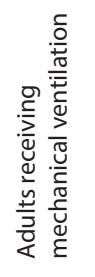

总
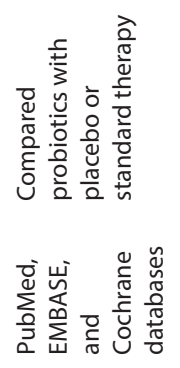

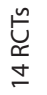

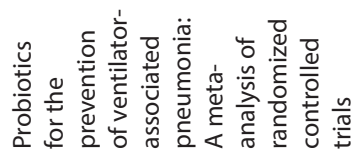

जิ

$\stackrel{\infty}{\simeq}$

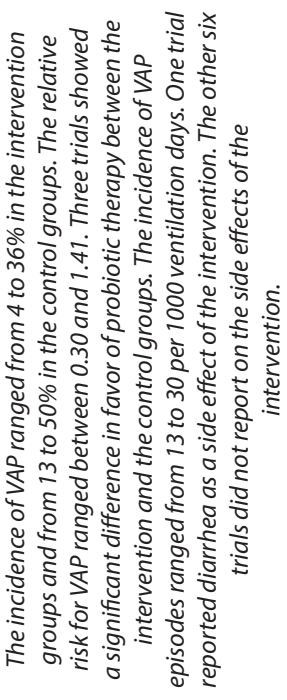

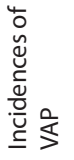

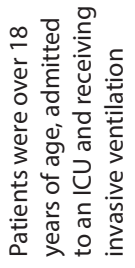

节

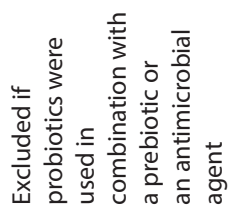

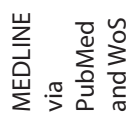

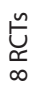

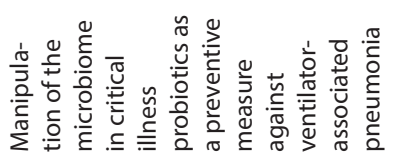

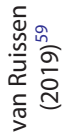

$\underline{9}$ 


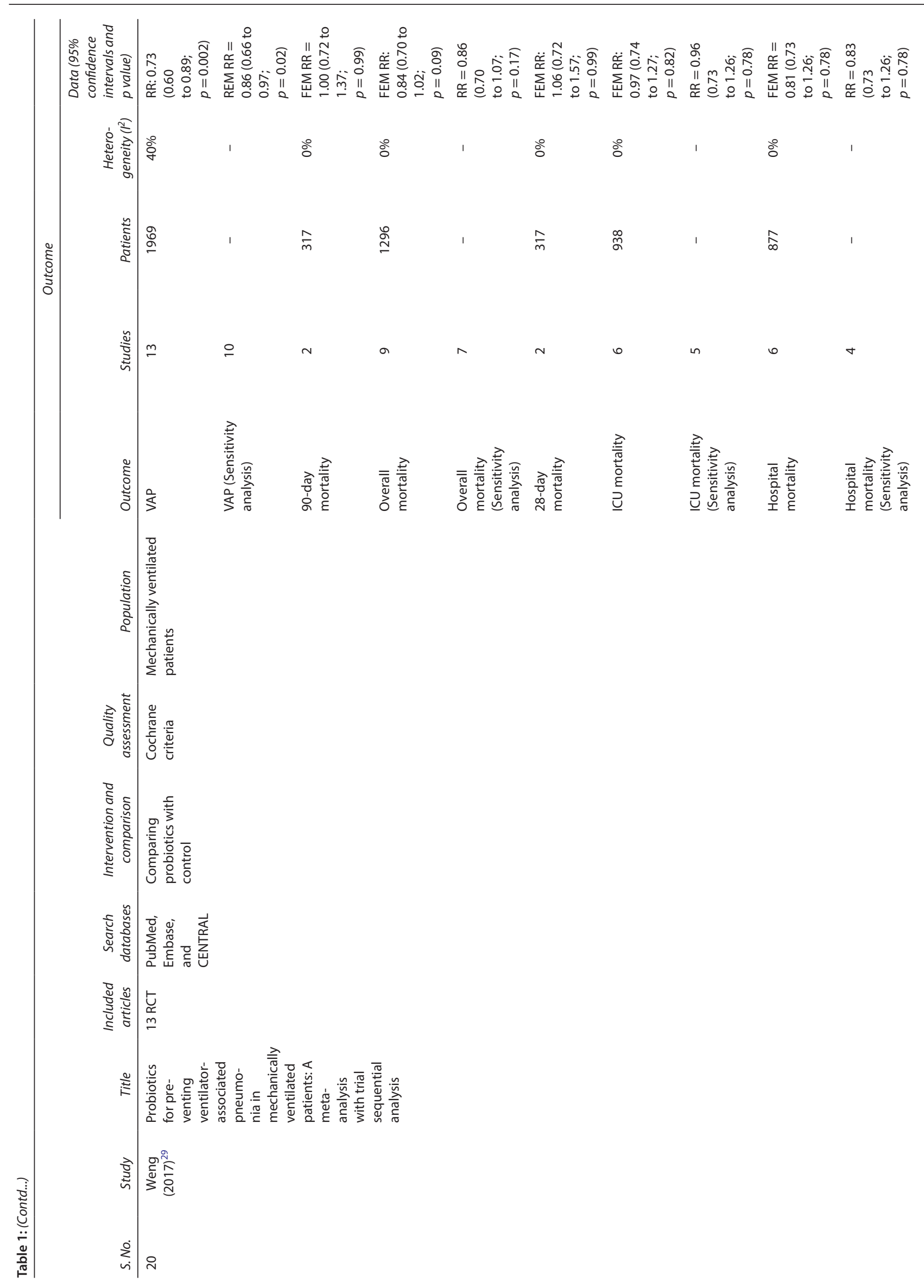




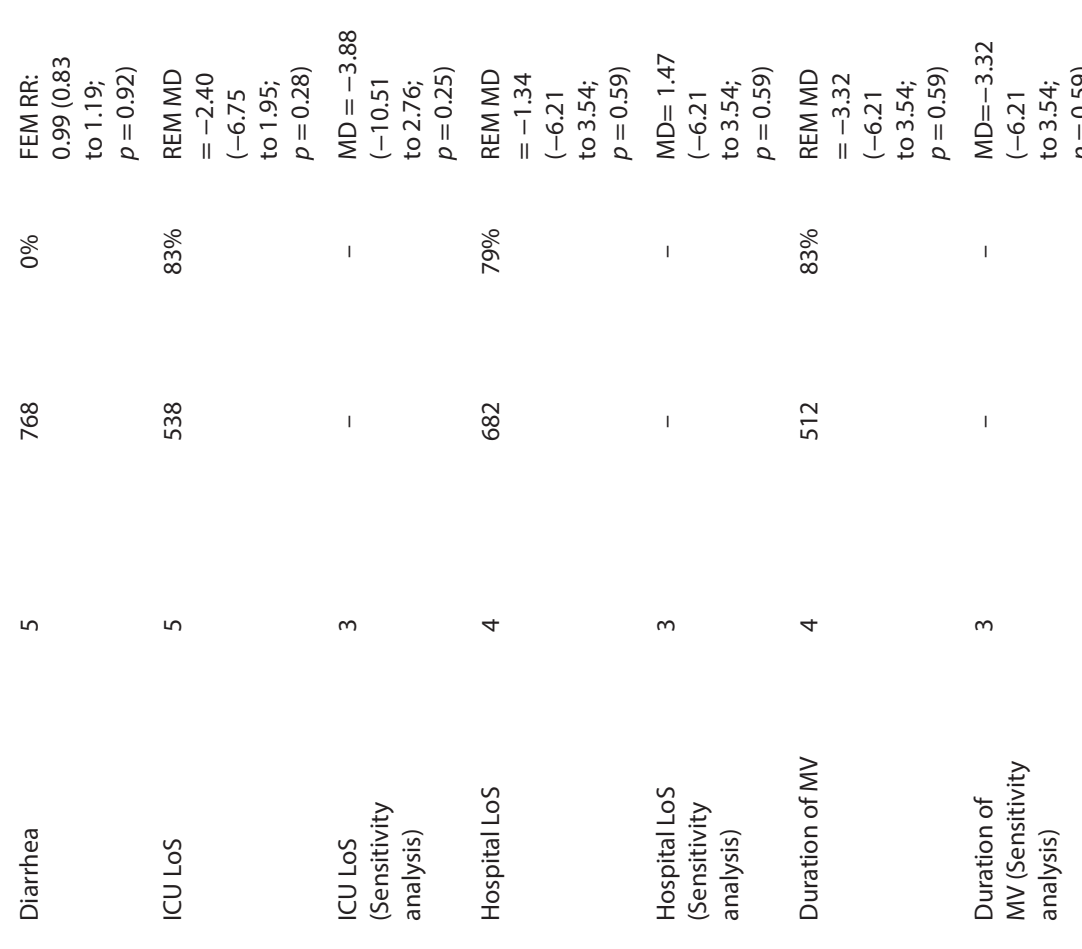




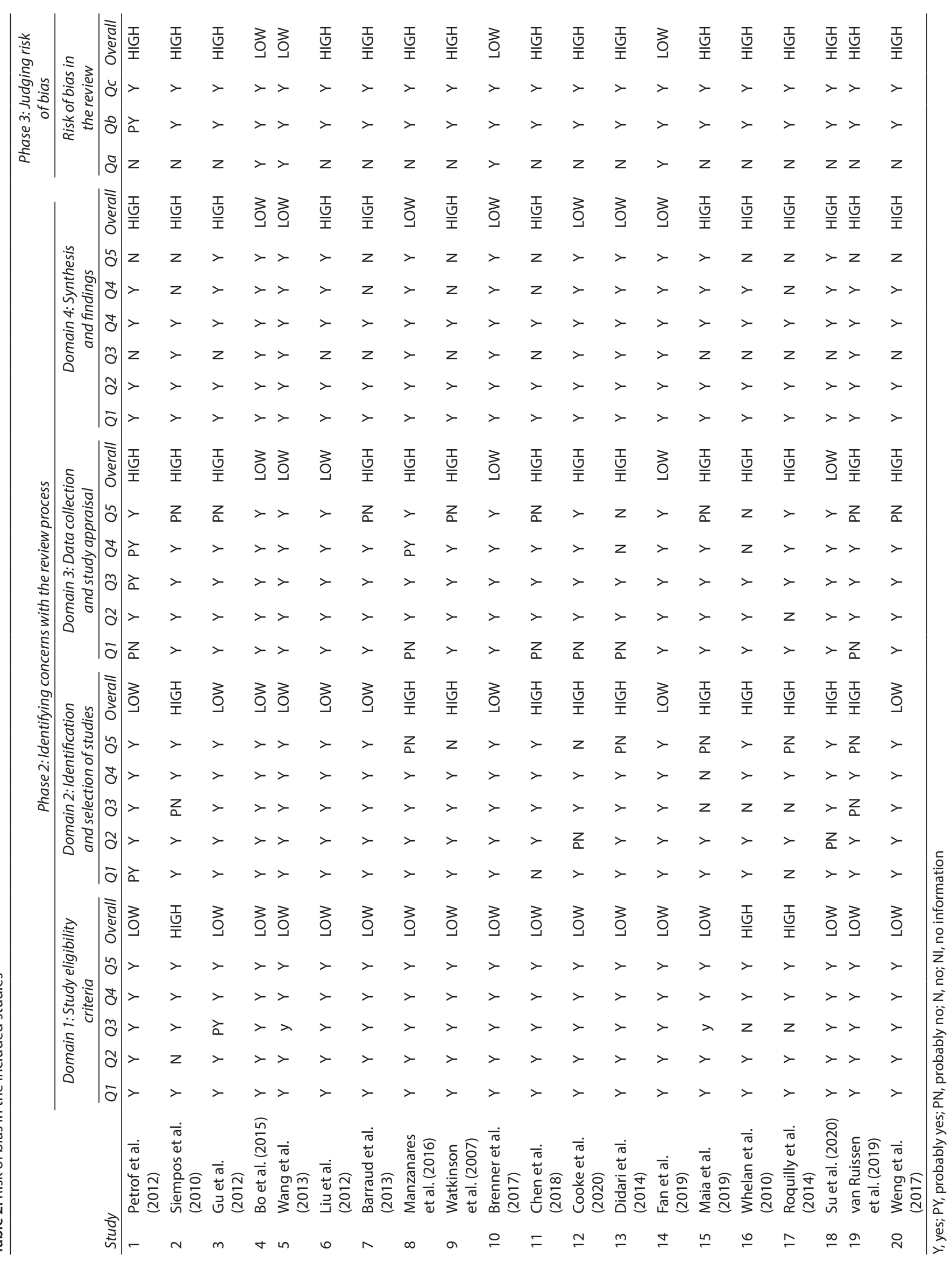




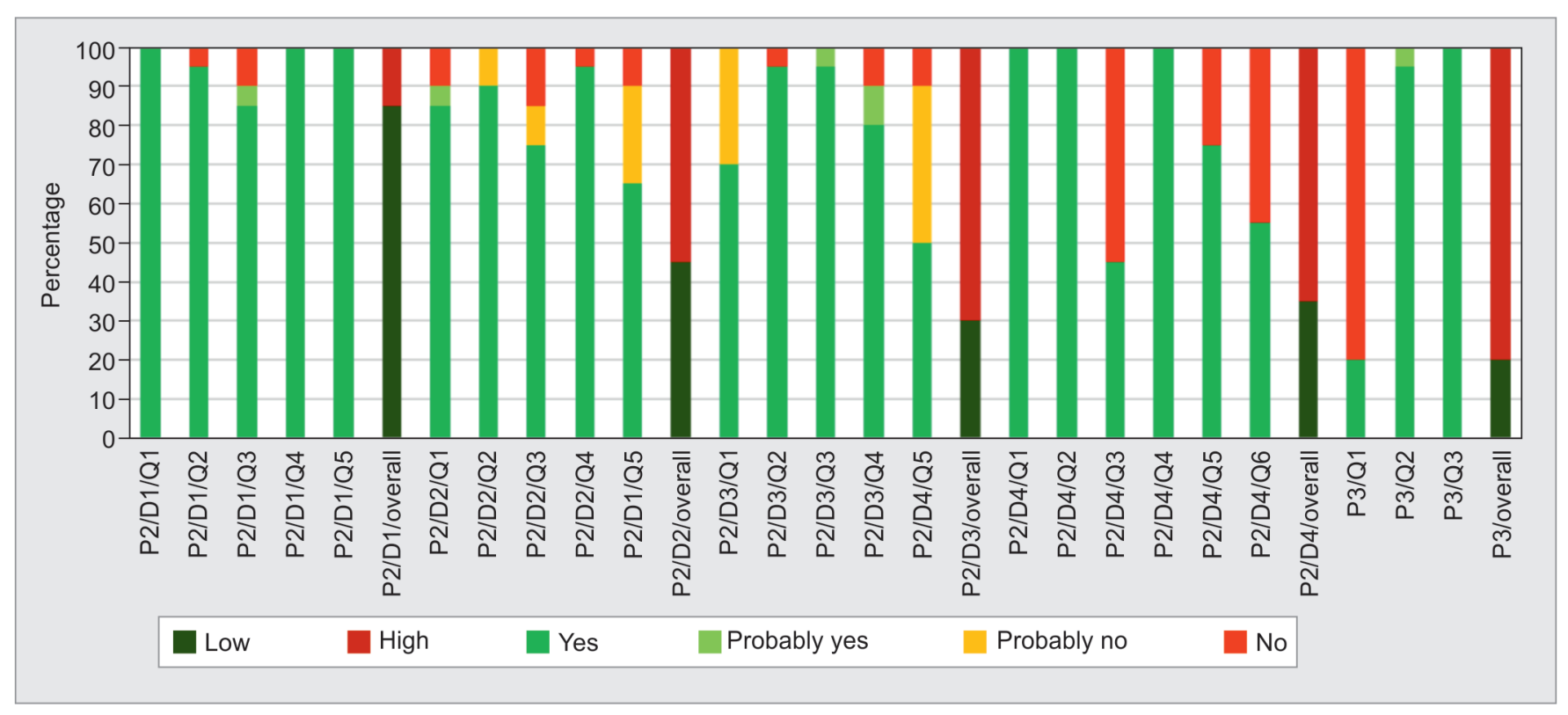

Fig. 1: Summary of the risk of bias assessment based on ROBIS tool. P, phase; $D$, domain; Q, question

assessment. Except for three studies, others assessed the RoB in their included studies, with Jadad score, Cochrane criteria, or other quality assessment tools. Finally, in terms of data synthesis biases, the similarity of pooled data was not considered in most of the studies. Also, the authors did not address the RoB assessment results in their final data synthesis, in about half of the studies. Overall, RoB assessment results indicated a high level of concerns about methodological misconduct in our included SRs.

\section{Discussion}

In this overview of SRs, all the reported outcomes regarding probiotic supplements were investigated. There are still a lot of controversies between different studies, which make it impossible to reach a reliable conclusion. Based on the current knowledge, we can say that probiotics may reduce the rate of VAP, nosocomial pneumonia, the overall infection rate, duration of mechanical ventilation, and antibiotic use in critically ill patients, but it has no or little efficacy in reducing the rate of mortality and length of hospitalization. In addition, there is not a significant association between using probiotics and the incidence of diarrhea.

Infection during ICU confinement is a worldwide challenge with a high mortality rate reaching about $60 \% .{ }^{35} \mathrm{VAP}$ is the second most common nosocomial infection in the United States, after catheter-associated urinary tract infections. ${ }^{36}$ It imposes a great financial burden on the healthcare system. The American Thoracic Society recommended the antibiotics for treatment of VAP in ICU patients, but the increasing concern of multidrug-resistant bacteria highlighted the importance of prevention strategies. ${ }^{37}$ A study comparing different interventions found probiotic a cost-effective intervention, in the prevention of VAP. ${ }^{38}$ Despite the possible efficacy of probiotic supplements in the treatment of VAP, its efficacy in the prevention of death is not considerable. It could be because of the limited attribution of VAP in the mortality of ICU patients. ${ }^{39}$ In other words, probiotics could not affect the other more prevalent critical illness of ICU patients, such as organ failure, and consequently could not significantly reduce the mortality rate.

The safety of probiotic supplements is not something worrying for many people. It has been used in foods and dairy products for a long time, and many people consider it a safe product. ${ }^{40}$ As many probiotics are sold as dietary supplements in the United States (US), it does not require FDA approval, so there is a lack of certain information on the safety of these supplements. In 2019, FDA stated that "Over-the-counter probiotics used in clinical trials to investigate their potential use for various disease conditions require more stringent quality controls to ensure purity and potency of the product".41 Also, the US National Institutes of Health $(\mathrm{NIH})$ believes that the risk of harmful effects of living microbiota is greater for critically ill patients. ${ }^{42}$ In 2011, a review of 622 studies found a lack of assessment and systematic reporting of adverse events in probiotic intervention studies and the safety of probiotic interventions was stilled unclear. ${ }^{43}$ In 2018, a SR of 384 probiotic, prebiotic, and synbiotic trials found that the broad conclusion of the safety of these supplements without reporting safety data is impossible. In this study, 53 trials involved hospitalized or critical care patients, and 37 of them included harm-related data in the publication. ${ }^{44}$ Studies also reported that probiotics might lead to fungemia and bacteremia ${ }^{45}$ and it should be used with caution in immune-compromised patients and older adults. ${ }^{46}$

A Cochrane review of pharmacological interventions for acute pancreatitis in $2017^{47}$ investigated the length of ICU stay in pancreatitis patients. None of 13 studies $(n=1,188)$ reported a consistent decrease in length of ICU stay. Also, a MA of RCTs in 2013 investigated the efficacy of pre-, pro-, or synbiotic supplements in trauma patients. According to this study's results, use of these supplements reduced the length of ICU stay (two trials; SMD, $-0.71 ; 95 \% \mathrm{Cl},-1.09$ to $-0.34, p<0.001)$, incidence of nosocomial infections (five trials; RR, $0.65 ; 95 \% \mathrm{Cl}, 0.45-0.94, p=0.02$ ), and VAP (three trials; $\mathrm{RR}, 0.59 ; 95 \% \mathrm{Cl}, 0.42-0.81, p=0.001$ ) in these patients, but no reduction in mortality (four trials; $\mathrm{RR}, 0.63 ; 95 \% \mathrm{Cl}$, $0.32-1.26, p=0.19$ ) was reported in this study. ${ }^{48}$ These two studies 
did not meet our inclusion criteria because of their different study population.

This umbrella review indicates the need for more welldesigned clinical trials rather than SRs. The restoration of gut microflora in critical illness trial (ROCIT) is one of the future studies. This Australian multicenter study can provide clear evidence about probiotic usage in ICU patients in a large sample size. ${ }^{49}$ The low quality of included studies is one of the most common limitations in the included SRs, ${ }^{25,29,50}$ which should be considered in future studies. Also, publication bias is one of the other concerns. ${ }^{28}$ The heterogeneity in different species was the common bias, which can harm the validity of the findings. This could raise from the limited published studies, which force the authors to pool heterogenic data to reach a single outcome. Different critically ill definitions and various diagnostic criteria for VAP are the other limitations, which should not be neglected. The different diagnostic criteria not only can result in great variation in the incidence of VAP but also can influence the mortality rate. ${ }^{51}$ The main strength of our study was the novel study protocol to assess the efficacy of probiotic supplements in critically ill patients based on the best available evidence. Also, adding other resources to search results of four databases led to the full coverage of published studies. Using a standard approach in conducting this review is the other strength of this study.

\section{Conclusion}

In conclusion, despite the various beneficial effects of probiotics in critically ill patients, there is not yet much evidence supporting their routine use and the available evidence is not sufficient enough to recommend the use of probiotics in critically ill patients. Further well-designed multicenter trials are needed to confirm their effects and benefits in these patients and to provide "evidence-based" recommendations.

\section{Acknowledgments}

The research protocol was approved and supported by Student Research Committee, Tabriz University of Medical Sciences (grant number: 66233).

\section{ORCID}

Amirreza Naseri @ https://orcid.org/0000-0001-9723-0109

Sepideh Seyedi-Sahebari ㄴ https://orcid.org/0000-0002-2623-226X

Ata Mahmoodpoor (1) https://orcid.org/0000-0002-4361-6230

Sarvin Sanaie 이 https://orcid.org/0000-0003-2325-5631

\section{References}

1. Tewari S, David J, Gautam A. A review on probiotic dairy products and digestive health. J Pharmacogn Phytochem 2019;8(3):368-372. Available from: https://www.phytojournal.com/archives/2019/ vol8issue3/PartH/8-3-57-432.pdf

2. FAO/WHO J. Report of a Joint FAO/WHO Working Group on drafting guidelines for the evaluation of probiotics in food. London, Ontario, Canada. April 30 and May 1, 2002. Available from: http://whoint/ foodsafety/fs_management/en/probiotic_guidelinespdf.

3. McFarland LV, Evans CT, Goldstein EJ. Strain-specificity and diseasespecificity of probiotic efficacy: a systematic review and metaanalysis. Front Med 2018;5:124. DOI: 10.3389/fmed.2018.00124.

4. Manzhalii E, Virchenko O, Falalyeyeva T, Beregova T, Stremmel W. Treatment efficacy of a probiotic preparation for non-alcoholic steatohepatitis: a pilot trial. J Dig Dis 2017;18(12):698-703. DOI: 10.1111/1751-2980.12561.

5. Liang D, Longgui N, Guoqiang X. Efficacy of different probiotic protocols in irritable bowel syndrome: a network meta-analysis. Medicine 2019;98(27):e16068. DOI: 10.1097/MD.0000000000016068.

6. Santacroce L, Charitos IA, Bottalico L. A successful history: probiotics and their potential as antimicrobials. Expert Rev Anti Infect Ther 2019;17(8):635-645. DOI: 10.1080/14787210.2019.1645597.

7. Szántó M, Dózsa A, Antal D, Szabó K, Kemény L, Bai P. Targeting the gut-skin axis - probiotics as new tools for skin disorder management? Exp Dermatol 2019;28(11):1210-1218. DOI: 10.1111/exd.14016.

8. Toh SL, Boswell-Ruys CL, Lee BSB, Simpson JM, Clezy KR. Probiotics for preventing urinary tract infection in people with neuropathic bladder. Cochrane Database Syst Rev 2017;9(9):CD010723. DOI: 10.1002/14651858.CD010723.pub2.

9. Rondanelli M, Faliva MA, Perna S, Giacosa A, Peroni G, Castellazzi AM. Using probiotics in clinical practice: where are we now? A review of existing meta-analyses. Gut Microbes 2017;8(6):521-543. DOI: 10.1080/ 19490976.2017.1345414.

10. Braga VL, Rocha LPS, Bernardo DD, Cruz CO, Riera R. What do Cochrane systematic reviews say about probiotics as preventive interventions? Sao Paulo Med J 2017;135(6):578-586. DOI: 10.1590/1516-3180.2017.0310241017.

11. Morrow LE, Wischmeyer P. Blurred lines: dysbiosis and probiotics in the ICU. Chest 2017;151(2):492-499. DOI: 10.1016/j.chest.2016.10.006.

12. Smith S, Roberts $S$. Nutrition support in critically ill obese adults. Nurs Crit Care 2015;10(6):26-35.DOI: 10.1097/01.CCN.0000472844.55184.31.

13. Petrof EO, Dhaliwal R, Manzanares W, Johnstone J, Cook D, Heyland DK. Probiotics in the critically ill: a systematic review of the randomized trial evidence. Crit Care Med 2012;40(12):3290-3302. DOI: 10.1097/CCM.0b013e318260cc33.

14. Morrow LE, Kollef MH, Casale TB. Probiotic prophylaxis of ventilatorassociated pneumonia: a blinded, randomized, controlled trial. Am J Respir Crit Care Med 2010;182(8):1058-1064. DOI: 10.1164/rccm. 200912-18530C.

15. Manzanares $\mathrm{W}$, Langlois $\mathrm{PL}$, Wischmeyer PE. Restoring the microbiome in critically ill patients: are probiotics our true friends when we are seriously ill? J Parenter Enteral Nutr 2017;41(4):530-533. DOI: $10.1177 / 0148607117700572$.

16. Haak BW, Levi M, Wiersinga WJ. Microbiota-targeted therapies on the intensive care unit. Curr Opin Crit Care 2017;23(2):167-174. DOI: 10.1097/MCC.0000000000000389.

17. Dhaliwal R, Cahill N, Lemieux M, Heyland DK. The Canadian critical care nutrition guidelines in 2013: an update on current recommendations and implementation strategies. Nutr Clin Pract 2014;29(1):29-43. DOI: 10.1177/0884533613510948.

18. McClave SA, Taylor BE, Martindale R, Warren MM, Johnson DR, Braunschweig $C$, et al. Guidelines for the provision and assessment of nutrition support therapy in the adult critically ill patient: Society of Critical Care Medicine (SCCM) and American Society for Parenteral and Enteral Nutrition (ASPEN). J Parenter Enteral Nutr 2016;40(2): 159-211. DOI: 10.1177/0148607115621863.

19. Elke G, Hartl WH, Kreymann KG, Adolph M, Felbinger TW, Graf T, et al. Clinical nutrition in critical care medicine-guideline of the German Society for Nutritional Medicine (DGEM). Clin Nutr ESPEN 2019:33:220-275. DOI: 10.1016/j.clnesp.2019.05.002.

20. Whiting P, Savović J, Higgins JPT, Caldwell DM, Reeves BC, Shea B, et al. ROBIS: a new tool to assess risk of bias in systematic reviews was developed. J Clin Epidemiol 2016;69:225-234. DOI: 10.1016/j. jclinepi.2015.06.005.

21. Moher D, Liberati A, Tetzlaff J, Altman DG, Group P. Preferred reporting items for systematic reviews and meta-analyses: the PRISMA statement. PLoS Med 2009;6(7):e1000097. DOI: 10.1371/ journal.pmed.1000097.

22. Fan Q-L, Yu X-M, Liu Q-X, Yang W, Chang Q, Zhang Y-P. Synbiotics for prevention of ventilator-associated pneumonia: a probiotics strainspecific network meta-analysis. J Int Med Res 2019;47(11):5349-5374. DOI: $10.1177 / 0300060519876753$. 
23. Su M, Jia Y, Li Y, Zhou D, Jia J. Probiotics for the prevention of ventilator-associated pneumonia: a meta-analysis of randomized controlled trials. Respir Care 2020;65(5):673-685. DOI: 10.4187/ respcare.07097.

24. Siempos II, Ntaidou TK, Falagas ME. Impact of the administration of probiotics on the incidence of ventilator-associated pneumonia: a meta-analysis of randomized controlled trials. Crit Care Med 2010;38(3):954-962. DOI: 10.1097/CCM.0b013e3181c8fe4b.

25. Gu W-J, Wei C-Y, Yin R-X. Lack of efficacy of probiotics in preventing ventilator-associated pneumonia: a systematic review and metaanalysis of randomized controlled trials. Chest 2012;142(4):859-868. DOI: 10.1378/chest.12-0679.

26. Bo L, Li J, Tao T, Bai Y, Ye X, Hotchkiss RS, et al. Probiotics for preventing ventilator-associated pneumonia. Cochrane Database Syst Rev 2014;10(10):Cd009066. DOI: 10.1002/14651858.CD009066.pub2.

27. Barraud D, Bollaert P-E, Gibot S. Impact of the administration of probiotics on mortality in critically ill adult patients: a meta-analysis of randomized controlled trials. Chest 2013;143(3):646-655. DOI: 10.1378/chest.12-1745.

28. Manzanares W, Lemieux M, Langlois PL, Wischmeyer PE. Probiotic and synbiotic therapy in critical illness: a systematic review and meta-analysis. Crit Care 2016;20(1):262. DOI: 10.1186/s13054-0161434-y.

29. Weng H, Li J-G, Mao Z, Feng $Y$, Wang $C-Y$, Ren X-Q, et al. Probiotics for preventing ventilator-associated pneumonia in mechanically ventilated patients: a meta-analysis with trial sequential analysis. Front Pharmacol 2017;8:717. DOI: 10.3389/fphar.2017.00717.

30. Whelan K, Myers CE. Safety of probiotics in patients receiving nutritional support: a systematic review of case reports, randomized controlled trials, and nonrandomized trials. Am J Clin Nutr 2010;91(3):687-703. DOI: 10.3945/ajcn.2009.28759.

31. Didari T, Solki S, Mozaffari S, Nikfar S, Abdollahi M. A systematic review of the safety of probiotics. Expert Opin Drug Saf 2014;13(2):227-239. DOI: 10.1517/14740338.2014.872627.

32. Cooke M, Ritmala-Castrén $M$, Dwan $T$, Mitchell $M$. Effectiveness of complementary and alternative medicine interventions for sleep quality in adult intensive care patients: a systematic review. Int J Nurs Stud 2020;107:103582. DOI: 10.1016/j.ijnurstu.2020.103582.

33. Maia LP, Levi YLdAS, do Prado RL, dos Santos Santinoni C, Marsicano JA. Effects of probiotic therapy on serum inflammatory markers: a systematic review and meta-analysis. J Funct Foods 2019;54:466-478. DOI: 10.1016/J.JFF.2019.01.051.

34. Sanaie $\mathrm{S}$, Ebrahimi-Mameghani $\mathrm{M}$, Hamishehkar $\mathrm{H}$, Mojtahedzadeh M, Mahmoodpoor A. Effect of a multispecies probiotic on inflammatory markers in critically ill patients: a randomized, doubleblind, placebo-controlled trial. J Res Med Sci 2014;19(9):827-833. PMID: 25535496.

35. Vincent JL, Rello J, Marshall J, Silva E, Anzueto A, Martin CD, et al. International study of the prevalence and outcomes of infection in intensive care units. Journal of the American Medical Association 2009;302(21):2323-2329. DOI: 10.1001/jama.2009.1754.

36. Timsit J-F, Esaied W, Neuville M, Bouadma L, Mourvllier B. Update on ventilator-associated pneumonia. F1000Res 2017;6:2061. DOI: 10.12688/f1000research.12222.1.

37. Arthur LE, Kizor RS, Selim AG, van Driel ML, Seoane L. Antibiotics for ventilator-associated pneumonia. Cochrane Database Syst Rev 2016;10(10):Cd004267. DOI: 10.1002/14651858.CD004267.pub4.

38. Branch-Elliman W, Wright SB, Howell MD. Determining the ideal strategy for ventilator-associated pneumonia prevention. Costbenefit analysis. Am J Respir Crit Care Med 2015;192(1):57-63. DOI: 10.1164/rccm.201412-2316OC.

39. Melsen WG, Rovers MM, Bonten MJ. Ventilator-associated pneumonia and mortality: a systematic review of observational studies. Crit Care Med 2009;37(10):2709-2718. DOI: 10.1097/ccm.0b013e3181ab8655.

40. Doron S, Snydman DR. Risk and safety of probiotics. Clin Infect Dis 2015;60(suppl_2):S129-S134. DOI: 10.1093/cid/civ085.
41. FDA. FDA developing improved methodology for determining purity of probiotic products. Available from: https://wwwfdagov/vaccinesblood-biologics/science-research-biologics/fda-developingimproved-methodology-determining-purity-probiotic-products. Content current as of: 05/10/2019.

42. NIH. Probiotics: what you need to know. Available from: https:// wwwnccihnihgov/health/probiotics-what-you-need-to-know. 2019.

43. Hempel S, Newberry S, Ruelaz A, Wang Z, Miles JN, Suttorp MJ, et al. Safety of probiotics used to reduce risk and prevent or treat disease. Evid Rep Technol Assess (Full Rep) 2011(200):1-645. PMID: 23126627.

44. Bafeta A, Koh M, Riveros C, Ravaud P. Harms reporting in randomized controlled trials of interventions aimed at modifying microbiota: a systematic review. Ann Intern Med 2018;169(4):240-247. DOI: 10.7326/ M18-0343.

45. Lherm T, Monet C, Nougière B, Soulier M, Larbi D, Le Gall C, et al. Seven cases of fungemia with Saccharomyces boulardii in critically ill patients. Intensive Care Med 2002;28(6):797-801. DOI: 10.1007/ s00134-002-1267-9.

46. Doron SI, Hibberd PL, Gorbach SL. Probiotics for prevention of antibiotic-associated diarrhea. J Clin Gastroenterol 2008;42:S58-S63. DOI: 10.1097/MCG.0b013e3181618ab7.

47. Moggia E, Koti R, Belgaumkar AP, Fazio F, Pereira SP, Davidson BR, et al. Pharmacological interventions for acute pancreatitis. Cochrane Database Syst Rev 2017;4(4):CD011384. DOI: 10.1002/14651858. CD011384.pub2.

48. Gu WJ, Deng T, Gong YZ, Jing R, Liu JC. The effects of probiotics in early enteral nutrition on the outcomes of trauma: a meta-analysis of randomized controlled trials. J Parenter Enteral Nutr 2013;37(3):310317. DOI: $10.1177 / 0148607112463245$.

49. Litton E, Anstey M, Broadhurst D, Chapman AR, Currie A, Ferrier J, et al. Study protocol for the safety and efficacy of probiotic therapy on days alive and out of hospital in adult ICU patients: the multicentre, randomised, placebo-controlled Restoration Of gut microflora in Critical Illness Trial (ROCIT). BMJ Open 2020;10(6):e035930. DOI: 10.1136/bmjopen-2019-035930.

50. Chen C, Wang J, Yin M, Zhao Q. Probiotics are effective in decreasing the incidence of ventilator-associated pneumonia in adult patients: a meta-analysis of randomized controlled trials. Int J Clin Exp Med 2018;11(10):10269-10277. Available from: https://e-century.us/files/ ijcem/11/10/ijcem0071942.pdf

51. Ego A, Preiser J-C, Vincent J-L. Impact of diagnostic criteria on the incidence of ventilator-associated pneumonia. Chest 2015;147(2):347355. DOI: 10.1378/chest.14-0610.

52. Wang J, Liu K-x, Ariani F, Tao L-I, Zhang J, Qu J-M. Probiotics for preventing ventilator-associated pneumonia: a systematic review and meta-analysis of high-quality randomized controlled trials. PLoS One 2013;8(12):e83934. DOI: 10.1371/journal.pone.0083934.

53. Liu K-x, Zhu Y-g, Zhang J, Tao L-I, Lee J-W, Wang X-d, et al. Probiotics' effects on the incidence of nosocomial pneumonia in critically ill patients: a systematic review and meta-analysis. Crit Care 2012;16(3):R109. DOI: 10.1186/cc11398.

54. Watkinson PJ, Barber VS, Dark P, Young JD. The use of pre-pro-and synbiotics in adult intensive care unit patients: systematic review. Clin Nutr 2007;26(2):182-192. DOI: 10.1016/j.clnu.2006.07.010.

55. Tan M, Zhu J-C, Du J, Zhang L-M, Yin H-H. Effects of probiotics on serum levels of Th1/Th2 cytokine and clinical outcomes in severe traumatic brain-injured patients: a prospective randomized pilot study. Crit Care 2011;15(6):R290. DOI: 10.1186/cc10579.

56. Falcao de Arruda IS, de Aguilar-Nascimento JE. Benefits of early enteral nutrition with glutamine and probiotics in brain injury patients. Clin Sci 2004;106(3):287-292. DOI: 10.1042/CS20030251.

57. Brenner LA, Stearns-Yoder KA, Hoffberg AS, Penzenik ME, Starosta AJ, Hernandez TD, et al. Growing literature but limited evidence: a systematic review regarding prebiotic and probiotic interventions for those with traumatic brain injury and/or posttraumatic stress 
disorder. Brain Behav Immun 2017;65:57-67. DOI: 10.1016/j.bbi.2017. 06.003.

58. Roquilly A, Marret E, Abraham E, Asehnoune K. Pneumonia prevention to decrease mortality in intensive care unit: a systematic review and meta-analysis. Clin Infect Dis 2015;60(1):64-75. DOI: 10.1093/cid/ciu740.
59. van Ruissen MCE, Bos LD, Dickson RP, Dondorp AM, Schultsz C, Schultz MJ. Manipulation of the microbiome in critical illnessprobiotics as a preventive measure against ventilator-associated pneumonia. Intensive Care Med Exp 2019;7(Suppl. 1):37. DOI: 10.1186/ s40635-019-0238-1. 